\title{
Instructional Challenges: The Experiences of the Clothing and Textiles Teacher on Some Selected Topics
}

\author{
Jacqueline Ogoe \\ University of Education, Winneba, P. O. Box 25, Winneba, Ghana
}

\begin{abstract}
The study explored the challenges Senior High School Clothing and Textiles (C\&T) teachers face in teaching the concept "Fibres and Fabrics". The purposive and convenience sampling techniques were used to sample eleven (11) C\&T teachers. A self-developed interview guide was used to gather data via an online electronic survey and analyzed qualitatively. Findings from the study indicated that the C\&T teachers perceived the content of "Fibres and Fabrics" as suitable for the levels they teach. However, the participants had challenges stemming from limited knowledge, institutional and curriculum gap. Improvisation and adaptive teaching techniques were some measures participants adopted to manage the challenges they encounter. The study concludes that if the challenges identified in this study are addressed, the teaching and learning of "Fibres and Fabrics" would improve. Hence, the study recommends that $\mathrm{C} / \mathrm{T}$ teachers adopt comprehensive, innovative and technology-based teaching approach to facilitate lesson delivery and understanding.
\end{abstract}

Keywords: fabrics, fibres, instructional challenges, teaching learning resources, textile education

DOI: $10.7176 / \mathrm{JEP} / 11-22-08$

Publication date:August $31^{\text {st }} 2020$

\section{Introduction}

The reception of the right form of knowledge and skills is key to achieving the educational goals of a nation. Idris et al. (2012) perceived education as a base for national development. Hoffman, Collin, and Schickedanz (2015) pointed out that the aim of educating individuals is to help them "conceptualize understanding" of what they are taught. A major objective of the Ghanaian educational system is to equip individuals with knowledge and employable skills to enable them contribute meaningfully towards the development of the nation (Forster, et al 2017). However, the educational system is mostly challenged with teacher quality and lack of adequate facilities for effective lesson delivery of which the teaching and learning of Clothing and Textiles share similar sentiments.

Clothing and Textiles is among the elective Home Economics courses offered at all levels of education in Ghana (Forster et al. 2017). As one of the effective means for global survival, concepts in Clothing and Textiles focus on developing an understanding of key theoretical concepts and on practicing skills for the production of textiles and clothing for man to use. The course, among its numerous objectives, aims at equipping learners with scientific knowledge in textile fibres and fabric selection (Forster, 2016). Textile education introduces students to understanding the properties and end-use of fibres and fabrics while observing eco-fashion protocols during production as well as exposure to job opportunities. The elements that are taught as concepts in textile education are means that contribute to sustainable growth and development of economies.

Decisions consumers make on what to select to wear or use begin with knowing and understanding the properties of fibres and fabrics as well as textile behavior during use and care. Knowledge gained in textile education serve as a guide to becoming an informed consumer (Majory, (1986). Hence, textile concepts students receive at the Junior and Senior High Schools and the tertiary levels have focused on giving introductory understanding in fibres and fabric production and selection (Forster, 2016; Ministry of Education, 2007 and 2010). Implying that the understanding of concepts in textile fibres and fabrics can help the learners to become informed consumers.

Contents in textile fibres and fabric cover the definition of fibre and fabric related terms, sources of fibres, classification of fibres, identification of fibres, properties of fibres, end-use of fibres and fabrics, finishes given to fibres and fabrics, fabrication techniques and finishing (Forster, 2016). Majory (1986) perceived information processing on textile fibres as complex due to new developments and technology. This implies that "qualitative identification of textile fibres" need to be carried out to enable learners familiarized themselves with textile products available on the market. Although, fibre qualitative analysis can be difficult as expressed by Majory, fibre identification systems have been proposed by Forster (2016), MoE, (2010) and Majory (1986) to help both teachers and learners understand fibre and fabric related concepts. Udale, (2014) believed that textile designing and production begins with research. Forster (2016) highlighted visual inspection, Microscopic examination, burning test, absorbency test and solubility or chemical test with their corresponding testing characteristics for easy identification of fibres. Majory indicated that most fibre test done by burning are done to put the fibres into categories but not necessarily identify the specific fibre. If specific fibre identification is required, then a further test need to be looked at hence microscopic and chemical solubility tests were recommended as more accurate in determining specific fibre type (Forster, 2016; Majory, 1986). 
Majory (1986) posited that contemporary education ought to be backed by theories which should be explained to the learner. Concepts in fibres and fabrics may not be familiar to learners especially those at the beginning stage. Thus, requiring teachers to strategically use varying techniques and resources to improve understanding of concepts they teach. In the light of many challenges in the educational systems, the Home Economics teacher is expected to be 'adaptive' to changes (Ekuban, Gavor \& Amoako-Kwakye, 2015).

\section{Statement of the Problem}

The Clothing and Textiles curriculum has, over the years focused on giving learners basic scientific knowledge in textile fibres and fabrics. Textile scientists have documented basic steps for identifying textile fibres and fabrics, yet concepts in textile fibres seem not well understood by students. This is evidence as candidates for West African Senior School Certificate Examination (WASSCE) from 2013 to 2016 and 2018 had challenges in responding appropriately to questions on "fibres and fabrics" as indicated in the Chief Examiner's Report for Clothing and Textiles (West African Examination Council-WAEC, 2018). Amissah (2004) earlier attributed the challenges teachers encounter to curriculum gap and specifically mentioned lack adequate skills for students to practice concepts learnt in textiles. Although, Amissah did not indicate whether Textiles students' understanding of concepts in textile fibres and fabric had influence on students' inability to understand and practice the concepts, an assumption to this challenge might be true.

It is perceived that knowledge acquired through the concept of textile fibres and fabrics should help students become informed consumers to enable them select appropriate fibres and fabrics for use and through the understanding gained, explain the assumptions behind fibres and fabrics properties. In view of this, the curriculum has provided and suggested some guidelines by which concepts in textile fibres should be taught in both theoretical and practical terms. However, the concept of fibres and fabrics seem to be less delved into. Teachers seem to be battling with getting learners understand the concept of fibres and fabrics and so may skip some aspects of the concepts they find difficult understanding or ignore teaching such concepts. Since concepts in fibres and fabrics seem new to learners, Clothing and Textiles teachers need to use pictures, specimen and videos where necessary to explain concepts. The teachers are sometimes challenged in getting the requisite teaching learning resources to explain and demonstrate such concepts to learners. For the content in fibres and fabrics to be understood clearly by learners, attention needs to be given to instructional challenges teachers encounter and adopt effective means to improve teaching and learning of concepts. It is against this backdrop that the researcher sought to explore the challenges Clothing and Textiles Teachers face in teaching the concept of fibres and fabrics.

\section{Purpose of the Study}

The study purports to explore challenges Clothing and Textiles teachers encounter when teaching the concept of "Fibres and Fabrics".

\section{Objectives of the Study}

i. To explore teachers' views on the content of the concept "Fibres and Fabrics".

ii. To find out challenges teachers face when teaching the concept of "Fibres and Fabrics".

iii. To solicit teachers' views on systems that are adapted to minimize the challenges they encounter when teaching "Fibres and Fabrics".

\section{Methods}

The study adopted a descriptive survey to design and analyze data. The study employed a qualitative approach to explaining the challenges Clothing and Textiles teachers encounter when teaching the concept of fibres and fabrics. The qualitative study focuses on exploring phenomena to explain the meaning of issues about the phenomenon (Merriam \& Tisdell, 2016; Kusi, 2012; Denzin \& Lincoln, 2005). The researcher used an interview guide to collect data from Clothing and Textiles teachers in the Central Region of Ghana. The researcher adopted purposive and convenience sampling techniques to recruit Clothing and Textiles teachers who were willing to participate in the study.

The researcher adopted the Google form to design the instrument. Items on the instrument consisting of demographic information of participants, views of participants on content suitability, challenges of teaching fibres and fabrics, and strategies participants adopt to manage challenges they encounter were added into an electronic survey via Google form. A link was created and copied to participants via Whatsapp. Data generated was downloaded from the researcher's email account for analyses. Descriptive and thematic analyzes were used to explain and discuss findings from the survey.

\section{Results}

Ten participants who were all females responded to the survey. Participants' ages ranged between 30 to 50 years. All participants have obtained a degree or higher academic qualification with teaching experience in Clothing and 
Textiles ranging from 1 to 20 years and above.

Research Objective One: Teachers Views on the Content of the Concept "Fibres and Fabrics"

This research question sought to find out Clothing and Textiles teachers views on suitability of the content covered in "Fibres and Fabric" for the level they teach. Participants generally presented mixed views on this theme as few found the concept be good for the level others expressed varying reasons that affect the suitability of the contents. Participant 1 and 9 found the content suitable for the learners at that level. "The content is ok for the students' level" (Participant 1), "The content suits the level I teach" (Participant 9).

Sampled views of participants who had different opinion on the suitability of the content of fibres and fabrics for the levels they teach are as follows:

"The content is less suitable since it is too lengthy for SHSI" (Participant 2). Participant 3 and 7 added: "It is taught at SHS 1 and most students find it boring because it takes a long period for the topic to be covered" (Participant 3). "It is too technical and abstract for the students to understand" (Participant 7).

Research Objective Two: Challenges Teachers Face When Teaching the Concept "Fibres and Fabrics"

This question sought to identify the challenges $\mathrm{C} / \mathrm{T}$ teachers face in teaching the concept of fibres and fabrics. The responses covered, institutional and personal challenges $\mathrm{C} / \mathrm{T}$ teachers face. Responses from participants are presented below:

\section{Institutional Challenge}

All participants generally shared that they lack adequate resources to undertake practical testing on the concepts. Participants mentioned lack of facilities, equipment, tools and materials to carry out fibre and fabric testing and identification as challenging.

\section{Personal Challenge}

The participants shared challenges they found personal to their effective delivery skills on the concept of "Fibres and Fabrics". Sampled responses shared include:

"Sometimes getting the attention and understanding of the students is difficult because almost everything is taught in abstract" (Participant 1)

"Some aspects are challenging to me like detecting fibres by appearance characteristics" (Participant 2).

"Personally I don't know how to use the microscope so I can't teach the students how to view fibres under the microscope" (Participant 3)

"Sourcing the actual raw materials (fibres) from which the fabrics are produced is difficult. Also, materials for research are few" (Participant 6).

Participants were generally challenged by having adequate knowledge to conduct research on fibres and fabrics as well as their inability to get real materials (samples) for explaining and demonstrating concepts in "Fibres and Fabrics". Forster (2016) attributed these challenges with the experience of the textile analyst. Several studies on teacher quality have attributed inadequate instructional resources utilization as a major challenge to the teacher (Nyawira, 2015; Mutai, (2011). Wasiche, 2006). Nyawira (2015) emphasized the effects of using less teaching learning resources on teachers' output. Nyawira advised that "For resources to be properly utilized, teachers need to have ample time to select and organize appropriate resources for each particular lesson" and further, encouraged teachers to improvise where necessary.

\section{Students' Reactions during Lessons in Fibres and Fabrics}

This question was a follow-up question on the challenges teachers face in teaching the concept of fibres and fabrics. All participants admitted that students' reactions are basically on being boredom, difficulties in understanding some of the concepts, inability for learners to pronounce some key words and understand terms in relation to fibres and fabric.

Sampled statements are below:

On lack of interest, Participant 1, 3,5 and 7 shared:

"You could see from their faces that they don't really enjoy the lesson" (Participant 1). "At the beginning it seems interesting but later find it boring" (Participant 3). Similar view was shared by Participant 5 "Some are not able to keep the characteristic of the various fibres so do not like the topics" whilst participant 7 simply shared: "Interest is low on fibres"

Participant 2 however, associated students' experiences to this challenge with loaded content and commented that: "The students usually say the properties are many, similar and sometimes confusing" while Participant 7 attributed this to lack of understanding by stating that "Some students find it difficult to understand it especially the sources of man-made fibre".

Participant 2 and 4 thought otherwise, since their perspectives portrayed mixed reaction.

"The interest prevails when enough resources to support teaching is available. - making their textile albums is great fun for students but sometimes they don't get the actual make up of some blended/mixed fibres because the laboratory test has not been conducted, though other tests such as observation and touching contribute" (Participant 2).

"Learners react positively to the concept fibres and fabrics and especially when samples are shown" 
(Participant 4).

It emerged from the data that students exhibit low interest when lessons are taught in abstract. However, if samples are made available, students participate in the lessons actively. Ekuban et al. (2015 pp. 39-40) students' interests and desires are key to effective learning. As indicated by participants 2 and 4, learners interest arouse when samples of the fibres are available and displayed.

Research Objective Three: Teachers' views on strategies adopted to minimize challenges faced when teaching "Fibres and Fabrics"

The study further explored participants' views on strategies adopt to manage the challenges they find when teaching the concept of "Fibres and Fabrics". It emerged from the data gathered that innovative teaching approaches were adopted by the participants.

Sampled views are outlined below:

"By showing textiles album with specimen of fibres/fabrics pasted in to make the lesson more interesting" (Participant 1).

"I resort to resource person for more information and use the internet for research to enable me explain the concepts better to the learners" (Participant 2)

"I sometimes interchange the topic to teach a topic not related to fibres and fabrics then later in the term I continue to teach the fibres" (Participant 3).

"Make the lesson interesting and lively with the use of TLMS, demonstrations and practicals" (Participant 4)

"I do my best to use available relevant and supporting learning materials to enhance understanding to some extent" (Participant 6)

"I mostly resort to use of videos to explain to students, practicals I am limited to undertake with students" (Participant 8).

Data gathered from this theme indicated that the participants adopt some strategies to manage the challenge they face in teaching the concept of Fibres and Fabrics. While some participants improvised to get learners understand the concepts, others try to be innovative by incorporating technology through internet search and video presentation in the teaching and learning (Participant 2, 6 and 8). Mæland and Espeland (2017) emphasized on the importance of improvisation in the teaching and learning process. Dehlin (2012) perceived improvisation as means of learning what is not real but realized. Thus, improvisation in education allows teachers and learners to use materials that have replica of the original one, to explain or demonstrate concepts.

\section{Conclusions}

Based on the findings of this study, the researcher concludes that the content covered under "Fibres and Fabrics" suit the level of the learners implying that the objectives of these concepts as outlined in the curriculum, are achievable when all other odds are held constant. Also, the findings indicated that lessons in "Fibres and Fabrics" are challenged by practical demonstration and sourcing of materials for demonstration and fibre/fabric portfolio development. These could be attributed to lack of expertise on the part of the teachers and probably lack of exposure to some fibres and fabrics or probably such fibres and fabrics do not exist in the Ghanaian setting.

These if not properly managed may affect the teacher's role as a facilitator (Jagtap, 2015) thus challenging the traditional role of the teacher as conveyor of knowledge (Hoidn, 2017). In spite of the challenges the teachers experienced, they adopt strategies they find useful to deliver lessons on the theme as mandated. However, the effective delivery of the concepts should be of concern. Clothing and Textiles are encouraged to "devote more time on the practical aspect" of the course as emphasized by the Chief Examiner (WAEC, 2018). Therefore, for a lesson to be successful, it should be well planned and organized by the teacher.

\section{Recommendations}

The study recommends that:

1. Teachers adopt modern innovative teaching techniques such as downloaded online video on fibre testing, and use of PowerPoint presentations of concepts.

2. The study again recommends that teachers should improvise where necessary and adopt technology-based teaching and learning processes in lesson delivery since technology adoption have the advantage of sustaining learners' interest (Mæland \& Espeland, 2017; Jamieson-Procter et al., 2013).

3. Clothing and Textiles teachers are encouraged to be more proactive and adaptive by researching more on fibres and fabrics to help in lesson delivery. This can be achieved through the use of the internet to search, download and upload information deemed necessary for use during lessons in fibres and fabrics.

4. Clothing and Textiles teachers should team-up with science resource experts in their schools to offer assistance in carrying out some practical lessons such as fibre/fabric identification.

5. The Ghana Home Economics Association (GHEA) should plan and organize in-service training for Clothing and Textiles teachers to upgrade and update teachers' knowledge on current teaching trends. 
6. The teacher education institutes in Ghana should organize refresher courses on concepts that Senior High School teachers find challenging.

\section{References}

Amissah, E. R. K. (2004). Appraisal of Textiles Syllabi and their delivery in Schools and Colleges (Doctoral dissertation).

Dehlin, E. (2012). Fleshing out everyday innovation: Phronesis and the either-or distinction between technical rationality and improvisation in knowledge. In T. S. Pitsis, A. Simpson \& E. Dehlin (Eds.). Handbook of organizational and managerial innovation. Edward Elgar Publishing.

Denzin, N. K., \& Lincoln, Y. S. (2005). The SAGE Handbook of Qualitative Research (3rd Ed.). Thousand Oaks, CA: Sage Publications, Inc.

Ekuban, G., Gavor, M. E. \& Amoako-Kwakye, F. (2015). Methods of teaching Vocational Studies: VOTEC III. University Printing Press, Cape Coast.

Forster, P. (2016). Clothing and Textiles ( $2^{\text {nd }}$ Ed). Accra. Winmat Publishers Ltd

Forster, P., Quarcoo, R., Ashong, E. L., \& Ghanney, V. (2017). Views of Teacher-Trainees on Clothing and Textiles Education in Two Teacher Education Universities in Ghana. World Journal of Education, 7(1), 113.

Hoffman, J. L., Collins, M. F., \& Schickedanz, J. A. (2015). Instructional challenges in developing young children's science concepts: Using informational text read-alouds. The Reading Teacher, 68(5), pp. 363-372.

Hoidn, S. (2017). Student-Centered Learning Environments in Higher Education Classrooms. New York: Palgrave Macmillan.

Idris, F., Hassan, Z., Ya'acob, A., Gill, S. K., \& Awal, N. A. M. (2012). The role of education in shaping youth's national identity. Procedia-Social and Behavioral Sciences, 59, 443-450.

Jamieson-Procter, R., Albion, P., Finger, G., Cavanagh, R., Fitzgerald, R., Bond, T. \& Grimbeek, P. (2013). Development of the TTFTPACK Survey Instrument. Australian Educational Computing, 27(3), pp. 26-35.

Jagtap, P. (2015). Teachers role as facilitator in learning. Scholarly Research Journal for Humanity Science and English Language, 3901-3906.

Kusi, H. (2012). Doing qualitative research: A Guide for Researchers. Accra-New Town, Emmpong Press.

Mæland, K., \& Espeland, M. (2017). Teachers' Conceptions of Improvisation in Teaching: Inherent Human

Quality or a Professional Teaching Skill? Education Inquiry, 8(3), 192-208.

Majory, L. J. (1986). Introduction to Textile Science (5 ${ }^{\text {th }}$ Ed.). USA, Suanders College Publishing.

Merriam, S. B., \& Tisdell, E. J. (2016). Qualitative Research: A Guide to Design and Implementation (4th Ed.). San Francisco: Jossey-Bass.

Ministry of Education, Republic of Ghana (2010). Teaching syllabus for clothing and textiles (Senior High School $1-3)$. Accra, Ghana: Curriculum Research and Development Division (CRDD).

Ministry of Education, (2007). Teaching syllabus for basic design and technology (Junior High School 1-3).

Accra- Ghana: Curriculum Research and Development Division (CRDD).

Mutai, J. K. (2011). Attitudes towards learning and performance in mathematics among students in selected secondary schools in Bureti District, Kenya (Doctoral dissertation, Masters Dissertation).

Retrieved from: http://irlibrary. ku. ac. ke/bitstream/handle/123456789/609/JACKSON\% 20KIPRONOH. pdf). Accessed on $7^{\text {th }}$ July 2020.

Nyawira, W. J. (2015). Challenges Facing Teachers in Utilizing Instructional Resources when Teaching Mathematics in Public Secondary Schools in Nairobi County, Kenya. (Unpublished Masters Thesis), Kenyatta University. Nairobi: Kenya.

Udale, J. (2014). Textiles and Fashion: Exploring Printed Textiles, Knitwear, Embroidery, Menswear and Womenswear. A\&C Black.

Wasiche, J. L. (2006). Teaching Techniques That Enhance Students Performance in Mathematics in Selected Public secondary schools in Butere-Mumias District. Kenya. (Unpublished M. Ed Thesis). Kenyatta University.

West African Examination Council (WAEC) (2018). Clothing and Textiles: Chief Examiner's Report for.

Sidmach Technologies Limited.-Nigeria.

Retrieved from: https://waeconline.org.ng/e-learning/Clothing/Clothmain.html. 